This is an accepted manuscript of an article published in the Sport Management Review. The Verson of Record is available online: http://dx.doi.org/10.1016/j.smr.2014.09.005

Running head: SPORT AND PUBLIC HEALTH

\begin{abstract}
In an effort to determine how sport could be better positioned on the public health agenda, three community physical activity programs aimed at combating obesity were examined to determine the benefits residents seek through their participation. Using a case study approach and critical framework, assumptions and presumed knowledge of these public health programs were drawn out through site visits and interviews. A total of 42 interviews with community leaders, program organizers, and residents in each community were conducted. The results reveal that new approaches need to be considered for promoting greater levels of participation in U.S. community sport and other leisure-time physical activity programs. Instead of the commonly emphasized benefits of physical health or appearance, the results demonstrate that hedonic rewards and opportunities for social interaction are two overlooked, yet primary benefits sought by participants. This research suggests that concerted efforts to focus on the hedonic feelings and social aspects can potentially lead to increased sport participation and holistic health. Such an approach may help better address vital public health policy issues while demonstrating the distinctiveness and utility of sport.
\end{abstract}

Keywords: community; sport policy; public policy; physical activity; sport development

(c) 2014. This manuscript version is made available under the CC-BY-NC-ND 4.0 license http://creativecommons.org/ licenses/by-nc-nd/4.0/ 
This is an accepted manuscript of an article published in the Sport Management Review. The Verson of Record is available online: http://dx.doi.org/10.1016/j.smr.2014.09.005

SPORT AND PUBLIC HEALTH

\section{What about Sport? A Public Health Perspective on Leisure-time Physical Activity}

\section{The absence of sport}

Public health issues often require the involvement and commitment of stakeholders from various industries and disciplines. Addressing modern health issues also requires new ideas to be brought into public health (Fineberg, 2012). Sport is one avenue that deserves more consideration on the public health agenda, especially in the United States. As Chalip (2006) highlighted, sport is but one form of physical activity. Along with sport, exercise (e.g., aerobics, strength training), physical recreation (e.g., dance, rock climbing), and purposive physical activity (e.g., climbing stairs, walking or biking for transportation) are among many options that can provide health benefits. Yet, sport has been an afterthought in U.S. public health campaigns, as evidenced by the almost complete absence of the word sport from public health discourse and promotions designed to get people more physically active (e.g., The Surgeon General's Vision for a Healthy and Fit Nation, 2010). There is also no mention of sport in the physical activity section of Healthy People 2020, a set of nationwide health promotion and disease prevention goals developed by the U.S. Department of Health and Human Services (2013a). Additionally, many sport organizations have contributed to this absence on the health agenda by predominantly focusing on developing elite athletes rather than encouraging mass sport participation. Such a focus fails to take into account that mass sport participation is not only useful for meeting public health goals, but also creates a wider talent pool for achieving competitive excellence (Chalip, 2011). The higher priority given to developing elite athletes in the United States has contributed to many viewing sport as a form of entertainment to be passively viewed, rather than an activity in which to participate (Lim et al., 2011). 
Along with this elite athlete focus, sport can be detrimental to one's health. Many youth sport programs do not provide the necessary amount of moderate to vigorous intensity physical activity due to participants standing around waiting for their turn to play (Bergeron, 2007; Leek et al., 2011). In these contexts, there often is an inappropriate coach-to-player ratio that results in too many structured drills, an overemphasis on winning, and/or excessive amounts of time spent discussing game strategies. Furthermore, previous research indicated that 1.4 million injuries occurred among 4.2 million high school athletes in nine sports (Comstock, Knox, Yard, \& Gilchrist, 2006). Some injuries are to be expected, but many are preventable. A hypercompetitive culture has come to stress that longer and more rigorous activity results in higher sport achievement, despite a body of research showing otherwise (Chambliss, 1989; Green, 2005; Vaeyens, Gullich, Warr, \& Philippaerts, 2009; Waddington, 2000).

The 2008 Physical Activity Guidelines for Americans recommends at least 150 minutes of moderate intensity physical activity per week for adults (U.S. Department of Health and Human Services, 2013b). Sport participation provides an opportunity for adults to meet both parts of the recommendation by simultaneously focusing on the quality of the activities (i.e., intensity) and the quantity of time (i.e., duration) spent participating. Sport can promote health, but as Chalip (2006) pointed out "We are not designing, managing, or marketing our sport organizations in ways that enable them to contribute to the promotion of public health" (p. 5). Thus, many continue to categorize sport as an arena that promotes deviance, violence, aggression, and risk-taking behaviors. In such cases, it is not sport per se that results in these antithetical outcomes, but rather how sport is haphazardly implemented and then left unevaluated. Given the attention and popularity of sport worldwide, it is clearly worth further exploring how sport could positively contribute to public health. 
While sport may be absent, physical activity is by no means a new idea for public health. Physical activity has long been promoted across the United States as essential for a healthy life (Pate et al., 1995). Yet, the fact remains that daily physical activity rates have not improved (Centers for Disease Control and Prevention, 2012). This is despite the increased recognition of the negative health consequences derived from physical inactivity and individuals having more leisure time than ever before (Chalip, Schwab, \& Dustin, 2010). Sport can serve as a means by which people become more physically active. While our focus and purpose is on how sport can be better positioned on the health agenda, it is vital to recognize and consider all avenues by which people are active.

\subsection{The domains of physical activity}

Overall leisure-time physical activity levels, which include sport, have remained fairly steady in recent years (Moore, Harris, Carlson, Kruger, \& Fulton, 2012). It should be noted, however, that these activities comprise only a small portion of daily physical activity (Brownson, Boehmer, \& Luke, 2005). Declining rates of physical activity have been attributed to changes in technology, the economy, society, and the built environment. The decrease in physical activity lends itself to an increase in sedentary activities, particularly those related to "screen time", such as video games, tablets, hand-held consoles, computers, and televisions (Katzmarzyk, 2010; Katzmarzyk \& Lee, 2012).

Daily physical activity is undertaken in a variety of contexts, or domains: occupational (e.g., manual labor), domestic (e.g., household tasks), transport (e.g., bicycling), and leisure-time (e.g., sports) (Armstrong \& Bull, 2006; World Health Organization, 2002). Leisure-time physical activity is done only for recreation and includes sport and planned exercise. Americans fail to meet daily physical activity levels not because of significant decreases in leisure-time physical 
activity, but rather due to declining physical activity in the other three domains (i.e., occupational, domestic, transport). In 2000, only $22 \%$ of the U.S. population worked in highactivity jobs, compared to $30 \%$ in 1950 , while individuals working in low-activity jobs rose from $23 \%$ in 1950 to $41 \%$ in 2000 (Brownson et al., 2005). Activity in the home also is declining due to the increased use of technology to complete household tasks (e.g., riding lawnmowers, snow blowers). Finally, Americans are driving more often than before, with $88 \%$ of trips to work being made in a car versus 67\% in 1960 (Brownson et al., 2005). Declines in these three domains of physical activity have resulted in an increase in sedentary activity and a decrease in total physical activity, creating a critical public health issue of physical inactivity. Because leisure-time physical activity rates have not declined, it is important to identify strategies to continue to improve these rates to compensate for declines in other physical activity domains. Consequently, understanding all the elements that engage individuals in leisure-time physical activity, whether it be in sport or any other leisure-time physical activity option, will be explored with the goal of better promoting sport in the public health discourse. Ultimately this would result in improved strategies for achieving physical activity and public health recommendations.

\subsection{Sport on the public agenda}

Since sport can often be viewed as a trivial activity that most people have experienced at some point and presumably know much about it, meaningful and responsible discussions regarding its role on the public agenda seldom take place outside of sport scholars (Chalip, 2006). Even when policymakers believe that sport has merit, they can still believe that other issues are more salient and thus not consider its utility, which is a challenge for sport managers (Kingdon, 1995; Pressman \& Wildavsky, 1973). Sport is also absent from the U.S. public health discourse due to a political culture that facilitates limited government involvement in most 
industries and organizations, especially sport (Chalip \& Johnson, 1996; Sparvero, Chalip, \& Green, 2008). While it is encouraging that some public health and sport scholars recently have begun to note the importance of policy (e.g., Casey, Payne, \& Eime, 2009; Smith \& Bird, 2004), there are still gaps in understanding if and how sport can be an effective tool to develop a population's health. This investigation attempts to fill that gap by better understanding the participants' perspective of sport and other leisure-time physical activity, including the benefits that participants seek. Doing so may help better reorientate sport as a means for social change, allow sport managers to learn from other leisure-time physical activities, and diversify programs such that more individuals become physically active.

In order to examine these issues in real world practice, the state of Texas in the United States served as the setting for this study. Operating through the Texas Governor's Advisory Council on Physical Fitness (GACPF) and under the political philosophy that policy should be crafted at the local level as often as possible, the Texas State Legislature appropriated $\$ 800,000$ over two year intervals (i.e., 2008-2009 and 2010-2011) for grants to communities to formulate and implement physical activity programs across the state. The increased attention given to obesity in the United States and its rising prevalence (cf. Sherry et al., 2010) served as the impetus for this grant program in Texas. Before proceeding to a description of the methodological approach and the results found in Texas, however, additional considerations for sport and public health policy need to be discussed.

\subsection{Current status of public health programs}

In research and public health programs attention is often focused on trying to develop permanent healthy lifestyles for youth. This focus results in many groups being marginalized and underserved through programs that were meant to serve the public good (Skinner, Zakus, \& 
Cowell, 2008). When governments and national sport governing bodies contemplate sport policies they often state mass participation as a central goal, but instead focus on developing elite youth athletes for competitive performance (Green, 2005; Sparvero et al., 2008). This inattention to grassroots sport participation has helped create the perception that active sport involvement is something only done during youth. This belief has contributed to a significant drop in sport participation after high school (Lim et al., 2011). While youth should not be ignored in public health programs, there is a fundamental problem with focusing solely on youth for sport or other physical activity participation. In other health programs designed for social change, such as reducing tobacco use or changing eating habits, adults are not disregarded as hopeless cases whose behaviors cannot be changed. The inclination of many researchers and policymakers is to attempt to teach an active lifestyle to youth with the assumption that such practice will be maintained throughout the lifespan. However, adults, rather than children, generate a majority of the rising medical and social costs resulting from physical inactivity. It would be irresponsible for policymakers to believe that they can curtail such costs by only focusing on the minority of the population that is under the age of 18. Further, children often need adult figures in their lives who model a physically active lifestyle (Cleland et al., 2011; Dixon, Warner, \& Bruening, 2008). Thus, it is vital to promote sport participation to the adult population.

When physical activity has been utilized to promote health, typically the discourse has been centered on the physical and mental health benefits that will be derived, including decreasing risk of chronic disease (e.g., cardiovascular disease and type 2 diabetes), assisting with weight management, improving mood, and alleviating depression and anxiety. Since the "obesity epidemic" has become a medical issue, public health and medical professions have held principle ownership of the public health concern while sport researchers have had little influence 
(Chalip et al., 2010). One critical reason that sport should be more widely considered for public health is due to its possibilities for holistic health enhancement (Wankel, 1997).

\subsection{Sport as a policy tool}

If sport is to be used as a policy tool, it is crucial that there is intentionality in the design of the program. Sport programs that realize benefits beyond physical wellness are deliberately structured and implemented to achieve the desired outcomes (Fraser-Thomas, Cote, \& Deakin, 2005; Green, 2005; Hartmann, 2003). There have been many assumptions about sport, mainly the belief in its inherent goodness, including for health (Green, 2008; McCormack \& Chalip, 1988; Skinner et al., 2008). This belief has led many program planners to presume that the mere provision of sport was all that was necessary to realize benefits of participation. Indeed, all public health programs must guard against the idea that merely providing opportunities will get people more physically active. Sport is a powerful social institution, but it is neither inherently good nor bad (Coalter, 2010; Green, 2008; Levermore, 2008). Sport is what managers make of it, not what policymakers hope it to be.

Thus far the literature has suggested that emphasizing skill development and personal competence (Chambliss, 1989; Wankel, 1997), enjoyment (Gould \& Carson, 2004; Green, 2005), and diversifying the activities played (Fraser-Thomas, Cote, \& Deakin, 2008) are crucial to encouraging participation and avoiding burnout or boredom. Shifting the focus towards skill development and enjoyment may be the best approach to making sport or other physical activity options more valued and establishing active lifestyles as the cultural norm, rather than the exception (Mowen \& Baker, 2009). As Chalip and colleagues (2010) discussed, most people view traditional physical activity options as uninteresting or uncomfortable. Even for people who are regularly active, many often try to distract themselves with music, television, and reading 
materials because the repeated movements found in many forms of physical activity are viewed as tedious and unenjoyable. Allowing participants to experience a range of physical activities, including sport, that are more playful in nature, rather than hypercompetitive, will allow for a diversity of personal competencies to be realized and additional enjoyment found in their experiences.

While a strong literature base has been built concerning public health programs and the management of sport as a policy tool, these perspectives have yet to be appropriately merged. As a result, a critical perspective is needed so that the benefits participants seek in their leisure-time physical activity are understood. This will provide sport managers and policymakers with knowledge needed to take a more holistic approach while also better positioning sport as a means for social change.

\section{Critical theory approach}

Critical theory is a useful framework for studying program processes and innovative public health approaches. A critical approach views the organization under study as operating in a wider sociopolitical context where dominant ways of thinking are historically entrenched. Critical theory seeks to challenge these dominant ways of thinking by giving voice to stakeholders regarding their preferences, beliefs, and openness to change (White, 1994). Thus, this allows for the crafting of healthier social practices. Critical research, as a result, has been shown to be valuable to sport policy analysis by explaining the prevailing social meanings ascribed to sport, which significantly influence subsequent policies (Berg \& Chalip, 2013; Chalip, 1995, 1996). By critically examining all aspects of programs, sport and other physical activity programs can be better understood, refined, and implemented (Sam, 2003). 
Therefore, this study utilizes a critical approach to examine the perceived benefits adults seek in their leisure-time physical activity to help determine how sport could be better positioned so that it is included more frequently on the public health agenda. Uncovering and understanding these factors could help increase the value of sport and improve public health programs.

\subsection{Method}

In an effort to better understand if and how sport could be better positioned on the physical activity and public health agenda, a case study and critical approach was used to examine the perceived benefits adults seek in a public health program.

\subsection{Research setting}

Three grant recipient communities in Texas charged with implementing wellness and fitness programs were selected for this study because they represented different community attributes that would allow for comparison. The three communities were given the pseudonyms of Dalton, Vista, and Dudley and were categorized by the GACPF as a large urban area, small urban area, and rural area, respectively (Table 1). It should be noted that due to the political nature of this research, some characteristics have been approximated in order to protect the identity of the communities, which was assured to study participants. Besides having different population sizes, each community possessed their own distinctive qualities, including resources and community histories that shaped the health experiences of their adult residents (Table 1).

\subsection{Procedure}

We initiated contact with the GACPF two years before the study commenced. Over those two years, we were introduced to people serving on the GACPF and local mayor's fitness councils, and attended a GACPF meeting to introduce ourselves and share our thoughts for this case study. Much like Frisby (2005) discussed in using a critical framework, we were honest 
with the participants and indicated that the research would likely reveal the difficulties and challenges in implementing a physical activity program. The GACPF provided contact information for the key informants in the selected communities (i.e., Dalton, Vista, and Dudley). These key informants, who served on the mayor's fitness councils and as the program leaders in their communities, were contacted and agreed to provide access for the study. Multiple key informants, with different backgrounds and leadership roles, were sought in each community in order to lessen the control one individual could have over the direction offered to the research team.

After several visits to each community were made, key informants introduced us to citizens in the community. Snowball sampling was then used to ensure the views of numerous people were obtained. In order to ensure full candor and anonymity, we explained to participants that pseudonyms would be used to conceal their identities and the names of their community. Participation was voluntary and interviewees had the right to stop the interview or prohibit inclusion of their comments at any point. An institutional review board assessed, approved, and ensured that the data collections and methods were in compliance with professional research ethics.

The interviews were semi-structured yet followed an interview guide based on the type of stakeholder participating (i.e., GACPF member, mayor's fitness council member, adult resident). Journaling and document analysis were employed and began as soon as the study commenced (Royse, Thyer, Padgett, \& Logan, 2006). At the end of each day spent in the participating communities, journaling consisted of recording observations and informal conversations that occurred. This method ensured the chronicling of fresh insights as they happened and did not require the research team to recall them later (Goulding, 2002). In regards to document analysis, 
the mayor's fitness councils and GACPF were asked to share any planning and promotional documents related to the communities' physical activity programs. Once the documents were attained, they were analyzed for local approaches to creating a more physically active population, commonalities and differences among communities, compliance with the application requirements of the GACPF, how sport factored in to their programs, and how the mayors' fitness councils had ensured the sustainability of their programs. The results of the journaling and document analysis helped the researchers contextualize the settings and construct an interview guide. This interview guide and semi-structured approach allowed the researchers to follow the conversation while providing some consistency between interviews (Munhall, 2007). Participants were asked to discuss what benefits they sought, whether the physical activity programs in their community met their wants and needs, how they participated in the programs, and how they would like to see the programs evolve. They were also asked to give their specific thoughts on sport and how they could see it fitting into their physical activity habits.

\subsection{Participants}

In order to capture adult residents' perceptions of the local physical activity programs and the derived benefits, 42 people were interviewed for this study. Four members of the GACPF, 16 citizens from Dalton, 12 from Vista, and 10 from Dudley were interviewed. Included in each community were mayors who also served on the mayor's fitness councils. Since the viewpoints of policymakers and constituents can sometimes differ significantly, this combination of participants provided a well-rounded perspective of the key stakeholder groups in the varying communities. The sample was fairly balanced in terms of gender ( 22 women, 20 men). All participants were asked during the interviews to describe in detail their typical physical activity in a normal week, including how sport fit into their overall activity participation. Such questions 
revealed a range of frequencies and modes by which participants were active. Thus, this study had a range of activity levels represented (i.e., ranging from regularly active to inactive).

\subsection{Data analysis}

After interviews were professionally transcribed, the data were analyzed with QSR International's NVIVO 9 software. The data were initially coded line by line to generate as many ideas and codes as possible. During the coding process, we were mindful of the existing literature on public health programs (Green \& Kreuter, 2005) and sport (Chalip, 2006; Chalip et al., 2010; Green, 2005, 2008; Lim et al., 2011). However, we were also open to new findings that emerged from the data. The initial coding process produced 35 first level codes. With the assistance of two independent researchers, the codes were then grouped to start identifying central themes and determining if the data were saturated. Intercoder agreement between the primary researchers and independent researchers was then met on the two primary overarching themes that emerged.

\section{Results}

Sport managers can learn from other forms of leisure-time physical activity. In addition to the appeal of sport, participants were afforded the opportunity to discuss what they commonly valued in their other physical activities. By locating common participant benefits between sport and other leisure-time physical activities, a new promotional approach for sport participation can emerge. Across all three cases, citizens cited numerous benefits for participating in sport and other leisure-time physical activities in their communities. Intercoder agreement was clearly met on the two primary overarching themes: hedonic rewards and social interaction. Each of these will be discussed with examples from both sport and other leisure-time physical activities 
offered. While not all participants' quotations can be included, the statements that best summarized and represented all 42 participants are provided.

\subsection{Hedonic rewards}

Hedonic rewards comprised the personal satisfaction and pleasure the participants described as a benefit that they seek in sport and other leisure-time physical activities. That is, the participants readily cited how much better they felt after engaging in sport and leisure-time physical activity and the enjoyment involved. It was evident that this was key to their participation. For example, Jimmy (Vista resident), Aaron (Dalton resident), and Mike (Dudley resident) added:

What I enjoy about the basketball is, just, it's a release of tension, and pressure, and it does make my body feel an improvement, and feel better, as I do physical fitness situations like that, or play the game of basketball. And it's just a game that I enjoy.

I'm terrible, but I'd love to play soccer, or ultimate Frisbee, or flag football... I might start doing more of that and workout less traditionally as I get older, just because it's fun. You know, and as I have kids I might do more stuff with them. But I'd love to play...I think it'd be fun to play soccer once a week.

The program has provided significant value to me... It helped me in reducing my weight, and in general I just feel better. I feel better about myself, and I feel good about my community because of it... So, it's fine to offer these programs, but you have to offer some significant marketing as well. With part of that marketing you have to tell about 
people who have had success, who have lost weight, or who feel better, or who just in general feel alive.

Although many of the residents discussed why they were not as physically active as they would like to be, they were still able to explain the hedonic feeling they experienced as a benefit of their activity. Repeatedly, the residents of all three communities stressed the value they placed on the hedonic rewards and how those were difficult to find through alternative activities elsewhere. What I have found that each day, and I do [workout] every morning, that I have more energy, I have more focus, I'm sharper. On days that I don't workout I don't feel as sharp or on top of it. It's kind of funny how you go expend so much energy to have energy and that's kind of how I feel. I feel very good during the day if I've worked out that day. (Howie, Vista resident)

I also feel better afterwards. I always dread the motivation up until the activity and then feel great afterwards. I feel like I have more energy. I feel like if I come in after working out and want to eat dinner, I'm going to fix a salad versus a burger, just because I feel healthier. (Sarah, Dalton resident)

Further, the results indicate that hedonic rewards are attractive and relevant to a broad spectrum of people. Often due to changes in age or physical ability, people can be intimidated at the prospect of restarting involvement in sport or another physical activity. Rebecca (Dalton resident) highlighted this: "Sometimes I'll just be intimidated and I'll think, 'Oh, well I'll be with other people that are way better than me, and that's not going to be very fun." Indications of intimidation, although unintentional, were also evident in sport and physical activity promotions within the communities. In fact, Vista citizens communicated to the mayor's fitness 
council that images of six-pack abs and "sculpted" bodies commonly used to promote various physical activity programs did nothing to motivate them to be physically active. Rather, those images displayed an unrealistic fitness standard that most felt was unattainable.

Regardless of how frequently someone is involved in sport and other leisure-time physical activities, their age, skill, and physical ability, the results illustrate that most people value the enhanced feeling they get from being physically active. The hedonic rewards that the participants described clearly added enjoyment to the physical activity. The data also indicate that this enjoyment and improvement in feeling has a lasting, beneficial effect that carries over into other areas of people's lives. Sheryl (Dudley resident) and Jennifer (Vista resident) explained:

The gym I enjoy knowing that I am more energized for the rest of the day; that my mind feels clearer; that it combats depression. I feel like I have a better attitude. I can tell when I don't exercise and I don't think it's that placebo effect; I think it is a true physical response to what goes on when I get that good exercise in the morning. And this was one of those days, you know, I got to the gym early and I'm still good.

And we all love basketball, you know, that's something we all like to do. So, it turned out to be almost the perfect event for us. Because the people that were there seemed to be having a good time, and thought it was fun... I have a good sweat and I feel like I've worked out hard. It just makes me feel better. You know, in every area. I mean I sleep better, my mood is better.

It is important to note that not all activities or uses of discretionary time result in feelings of pleasure and personal satisfaction (i.e., hedonic rewards) as found in sport and other leisure-time 
physical activities. More importantly these hedonic rewards are not confined to a select few options, but can be found in the multitude of sports and other leisure-time physical activities that are possible. In addition to the customary utilizations of gyms and yoga classes, participants discussed numerous sports and other leisure-time physical activities that offered hedonic rewards, such as kickball, tennis, swimming, cycling, soccer, running, hiking, kayaking, kickboxing, basketball, and racquetball.

In summation, the data exemplify how participation in sport and other leisure-time physical activities contributes to holistic health and participants continually highlighted that this was accomplished through the hedonic rewards they experienced.

\subsection{Social interaction}

The opportunity for social interaction and the sense of community that developed was the other most frequently cited reason the residents wanted to participate in sport and other leisuretime physical activities. This theme was coded as social interaction. Eric, a GACPF member, and Debbie, a Dalton resident, both highlighted this:

First of all, people tend to be more engaged with physical activity and more consistent with it if it's a group activity; they have other people they're doing it with, friends, teammates. There's an element of camaraderie and fun when you do it that way. People tend to stay motivated when it's not just them going to exercise in the morning by themselves. People have a better retention, from my experience, when they're involved either with a team or at least a group of people they're training and exercising, or they have a goal they're training toward. 
For me, exercise, I like for it to be social. You know, being in a class, having someone meet me there, or walking with friends has been a great thing to do with other new moms. It's been a huge part of my social life now.

In Dalton, the importance of social interaction was demonstrated by developing a sense of community and a cohesive team at the workplace through the opportunity to participate in sport and other leisure-time physical activities. Madeline and Richmond, both Dalton residents, explained:

You work very long hours. 60-hour work weeks are not uncommon with engineers. So the ability to, at lunch or late afternoon, be able to take an hour and a half break to go play basketball... they greatly appreciated it. And from an employer perspective we felt as though it contributed to productivity, because they could really incorporate a sense of community into their work life. So it kept them on the job longer.

One of the fringe benefits is that oftentimes these activities involve other people. So relationally, I feel that I'm being healthier. As opposed to sitting around watching a game and drinking beer with friends, it feels even better to go outside and throw a football or go for a jog.

Dudley provided a popular yoga class that served as a strong example of the possibilities for developing a sense of community through sport or other leisure-time physical activity programs. As outside observers, the enthusiasm people arrived to the class with and the extensive time they spent interacting with each other afterwards was a distinguishing feature that may often be absent in other physical activity contexts. 
And what we found is when you're in a group, and particularly if it's people you know, and they're friends, you have some connection, either school, or church, or you worked together, or something like that, you get better participation and better results. (Paul, Dudley council member)

It was clear from the Dudley case, participation in sport and other physical activities can play a critical role in fostering a needed sense of connectedness particularly among retirees who are more socially isolated or may have experienced the death of a spouse. Further, these relationships were not just confined to the physical activity setting, but carried over into other parts of the participants' daily lives.

...Through this (yoga) class I have met a lady. She and I have become friends and we have a regular meditation at my house once a month with some of these ladies from this group and some of them come from outside the group. So I've expanded my friends by ten or twelve, just from going to this class. So it's been in that respect beneficial. If they (sport managers and policymakers) get people out and get them interested in one another and the social aspect of it is important, almost just as important as the exercise itself. There are some of those ladies in there that have lost their husbands and they don't have a whole lot of friends and they come there and they feel very welcomed. Everybody tries to get to know one another at one point or another and speak to each other. (Julie, Dudley resident)

Sport and other physical activity programs are particularly meaningful when they have effects that reach beyond the program setting. Thus, in Dudley the yoga class did not just improve strength and balance for dozens of people, but offered a new avenue to possibly enhance the quality of life of the participants and the social connectedness of its citizens. 
Repeatedly, the interview responses illuminated that social interaction or connectedness in a community is just as important to many people as the physical and mental health benefits they experience, which should be considered more in public health programs. Further, in all three communities people cited certain groups that have been marginalized thus far, and sport represents a distinct tool available to public health to increase social inclusion in the future. The participants in this study recognized the sense of community that had developed through the programs, but they also did not understand the distinctiveness of sport and its possibilities for public health. Not all people will be attracted to participate in a yoga class or run by themselves at a local park. Sport programs are another avenue through which different segments of a population can be reached, such that more individuals are experiencing a sense of community within health promotion programs. For example, in Vista reestablishing a sport competition for local worksites was a primary focus to develop a sense of community while getting adults more active.

...But real team sports then there's the opportunity for engagement. You're looking for another team to play and so when you've got other companies in the community that have that same competitiveness and so now it's "my company and we played them last week and lost to them; we've got another opportunity to play for the championship", you build that kind of dialogue in the community... So I saw what it did for us as a company and again wellness and fitness and you've got people a bit more aware. And so people started to workout; they started a practice and so that practice is physical activity and you're doing that a couple of days a week and then you have a match or a game and guess what? People aren't thinking about it but you're working out two, three, four days a week doing something. And you're doing it for thirty or forty-five minutes; an hour. Next 
thing you know, "Well wait a second I've lost some weight or we're starting to work together as a unit better..." (James, Vista council member).

Across all three communities, it was evident that participants felt that the opportunity for social interaction through sport and other leisure-time physical activities was a noteworthy benefit. The social interaction helped formulate a sense of community and supportive network, and the data demonstrated this was a key benefit to participation.

\section{Discussion}

It should be noted that often times what is not in the data is just as important as what is in the data (Munhall, 2007). When asked what they enjoyed or valued about their participation, in almost every instance residents did not cite two of the most common emphases of contemporary sport and physical activity marketing: "it's good for you” and physical appearance. For decades, the public has been educated on the health benefits of being physically active. Yet, as Chalip and colleagues (2010) discussed, rates of inactivity or activity abandonment continue to increase. Promotional efforts emphasizing that physical activity is "good for one's health" will be unlikely to offer anything new or useful to the contemporary health discourse, or result in increased participation. Although well aware of the physiological benefits to increased participation, none of the participants cited such promotional efforts aimed at enhancing health as a significant motivational factor for becoming more physically active.

Next, the participants did not discuss improved body image as something they valued from their activity. Again, the residents of Vista clearly communicated that images of six-pack abs and "sculpted" bodies held little motivation or value for them. This is noteworthy and suggests that public health programs need to emphasize other benefits, specifically hedonic rewards and opportunity for social interaction, to more closely match what participants value in 
their sport and other leisure-time physical activities. Based on the results of this study it is vital for policymakers and sport managers to better understand the voices of the constituents who they serve.

In many ways, Green's (2005) sport development model is applicable to this study because its relevance is not just confined to elite sport development, but mass participation in sport and other leisure-time physical activities, as well. The model reveals factors that allow for recruitment, retention, and transition, which are all necessary to understanding sport and physical activity rates and commitment. During each of these participation stages, multiple motivations and available opportunities intermix to influence people's decisions to continue or to exit the sport or physical activity (Lim et al., 2011). For instance, the results demonstrated how entry and reentry into sport and other leisure-time physical activities was a challenge for participants. In all three Texas communities, participants often discussed how social influences and social opportunities (i.e., social interaction) recruited them into the activity or became a significant factor for why they wanted to continue their participation. Then at the retention stage, along with the social interaction and the resulting sense of community, the hedonic feeling (i.e., hedonic rewards) needed to be emphasized more. In other words, the personal satisfaction and energy gained from participation is clearly something our participants desired. The data noticeably revealed that both opportunity for social interaction and hedonic rewards were significant benefits that were salient to the participants and were not necessarily found elsewhere.

More research to determine how to maintain sport and physical activity participation during the transition from one life stage to another is needed. Green (2005) suggested that more community-based programs that cater to multiple motives and market segments are needed. The results of this study concur with such a recommendation, and further that work by specifically 
highlighting hedonic rewards and opportunities for social interaction as being key to accomplishing this. From a practical standpoint, the results indicate that showing someone who has attained elite physical shape will likely not resonate with most of the population and get more people physically active. However, promotions emphasizing feeling better (i.e., hedonic rewards) after participation in sport and other leisure-time physical activities may resonate more with people of all backgrounds and health statuses. This lesson should not just pertain to sport managers, but also to public health program leaders.

The results also point to the need to better emphasize the social relationships that can be formed in the program, which often serve as a strong source of encouragement for many people to sustain their involvement (Sherwood \& Jeffrey, 2000). Finding ways to increase the social interaction and resulting sense of community experienced was clearly linked to the enjoyment of the activity for those interviewed and is another avenue to reach additional segments of a community who have not yet been reached. Again, merely providing opportunities for sport and other physical activities will not likely suffice in allowing residents to realize the benefits from participation, including a sense of community. As the Texas communities showed, extensive planning and the manner in which programs are implemented can greatly influence the social benefits participants derive (Green, 2008; Warner, 2012). Finally, sport and other physical activities must be promoted in ways that are congruent with local cultural values and preferences (Coalter, 2010). If these conditions are taken into account and worked toward, rather than the simple provision of activity, such programs can make a positive, if limited, contribution to social regeneration (Coalter, 2007).

Sport and leisure-time physical activity have been found to be an important tool for creating opportunities for social interaction (e.g., Grieve \& Sherry, 2012; Warner, Bowers, \& 
Dixon, 2012) and developing a sense of community (e.g., Warner \& Dixon, 2011, 2013a;

Warner, Dixon, \& Chalip, 2012). "A sense of community arises out of the fundamental human need to create and maintain social bonds, to develop a sense of belonging and develop a sense of self-identity" (Skinner et al., 2008, p. 255). Experiencing a sense of community often fosters greater well-being and civic participation, but also has been shown to be key to program retention (cf. Kellett \& Warner, 2011; Warner, Kerwin, \& Walker, 2013; Warner, Shapiro, Dixon, Ridinger, \& Harrison, 2011). While social disengagement and isolation increasingly characterizes modern societies, sport and leisure-time physical activities represent one of the few traditional contexts that can still foster a sense of community (Lyons \& Dionigi, 2007; Warner, 2012; Warner, Dixon, \& Leierer, in press). This makes sport's absence from the public policy agenda intriguing.

In order for sport to have greater utility as a physical activity or public health policy tool, it is essential to consider how sport participation is defined in a given context. In a recent crosscultural study, both Korean and U.S. participants frequently considered passive sport spectating or fanship as sport participation. This was not as predominate among the Dutch participants in the study, who held a much broader definition of what sport could entail (Lim et al., 2011). Considering the Netherlands had remarkably $69 \%$ of males and $72 \%$ of females participating in sport, how sport has been defined and perceived in the U.S. context is noteworthy. Indeed, when asked about their sport participation, some of the Texas residents in this study cited common sport activities (e.g., basketball, tennis) while others answered that they only watch sport or that sport is mostly for young people's participation. Regardless of their activities, most residents did not consider their activity to be sport participation. In light of Lim and colleagues' work and the findings of this study, it is posited that a broader definition of sport may be beneficial in getting 
more individuals physically active and towards a cultural perception that sport can be participated in throughout the lifecourse. It is also intriguing that obesity rates in the United States more than doubled between 1985 and 2008, a time frame in which "competitive" sports also dramatically increased (Coakley, 2008). Clearly broadening the notion that sport is not just elite and competitive (cf. Warner \& Dixon, 2013b), but rather offers hedonic rewards and the opportunity for social interaction may be key to keeping more people physically active.

Since leisure-time physical activity is the only domain that appears to have remained consistent over time, it is imperative for public health policymakers, researchers, and practitioners to examine how leisure-time physical activity rates can continue to improve, especially in light of declining rates in the other domains (i.e., occupational, domestic, transport). Sport participation provides an avenue for increasing leisure-time physical activity rates. The results of this study clearly supported that participants seek hedonic rewards from leisure-time physical activity programs. For leisure-time physical activity in general, if participants are able to experience such rewards, adherence is likely to be enhanced due to the value most participants place on enjoyment and pleasure in any activity (Salmon, Owen, Crawford, Bauman, \& Sallis, 2003; Wankel, 1997). Again, the findings of this study make sport's absence from the public health agenda rather curious. Along with the opportunities for social interaction that can be found in sport, the experience of sport can be quite effective at facilitating hedonic rewards (Chalip, 2006). A key reason is due to the advantages of play that sport requires, which may be absent in other domains of physical activity (see Chalip et al., 2010). The hedonic rewards found through play serves as an intrinsic incentive for people to sustain their physical activity (Kilpatrick, Hebert, \& Bartholomew, 2005). 
From a policy perspective, more funding and resources should be made available for adult sports programs. Historically, funding for sports activities has been primarily allocated toward youth sports. Additionally, Healthy People 2030, the next 10-year agenda for improving the nation's health, should consider including a sport component, incorporating both youth and adult sporting activities under the physical activity umbrella. More research agendas focusing on the effect of sport participation on physical activity levels, physical health, and mental health would also be worthwhile. Funding sources, such as the National Institutes of Health, targeting the importance of sport participation in increasing leisure-time physical activity would be another important step toward addressing the issues related to declining physical activity. Finally, practitioners should consider developing programs that target adults and teach sporting skills, encourage sport participation as a means of achieving physical activity and public health guidelines, and support participation from individuals of all skill levels. These efforts have the potential to promote sport participation as a means of increasing leisure-time physical activity, which may ultimately improve daily physical activity levels and chronic disease prevention and management.

The results of this study also demonstrate that case studies and a critical framework can be an effective way to illustrate the complexities of public health issues and the intricacies of sport and physical activity programs. Case studies examine the dynamics present within a single setting or multiple settings, are especially effective in new topic areas, and can result in novel and empirically valid findings (Eisenhardt, 1989). It was beneficial to have comparison cases for this study because they allow researchers to better distinguish differences or similarities so false phenomena are not identified and novel findings in the data are captured (Weiss, 1994). Through the accumulation of idiosyncratic evidence from individuals and groups, larger social patterns 
can be understood (Sanger, 1996). Examining the dynamics between health promotion programs and its participants through the case study approach also complements a critical framework. With an "insider's" view, researchers, policymakers, and practitioners can acquire further understanding regarding participants' viewpoints, specific effects, and unanticipated consequences of a program. Further, those affected by the policy issue are able to help improve future programs.

Though it is beneficial to have multiple cases for comparison, as we found in this study, there is so much complexity involved in public health programs that novel insights can be gleaned from just a single case. Future research should consider conducting additional case studies in different settings to clarify what issues are similar or different for public health programs carried out in other communities, including other national contexts where the sociocultural value and usage of sport for public health can be quite different from the United States. Researchers conducting case studies must always guard against making grand generalizations when in fact some of their findings are idiosyncratic phenomena (Eisenhardt, 1989). However, through the gradual accumulation of idiosyncratic evidence from different case studies, public health programs can be understood and refined (Sanger, 1996).

While the study participants were from three different communities and were balanced in terms of gender and physical activity levels, conclusive findings cannot be presented for how sport and other leisure-time physical activities were experienced in such programs by people of various races or ethnicities. This is an important consideration for future sport or physical activity research since ethnic minorities can often be challenged with disparities in access and quality of such programs, which contributes to health disparities among the population (Taylor, Floyd, Whitt-Glover, \& Brooks, 2007). Snowball sampling, as used in this study, is particularly 
suitable when attempting to study specific populations that may be of interest to researchers who are not usually in the study setting (Royse et al., 2006). However, this approach can often result in a homogenous group for certain characteristics, which was realized with the lack of racial heterogeneity among the sample, and may be a potential source of bias. Researchers who rely on key informants who serve as gatekeepers to access a research site must be cognizant of this challenge and the limitations it can impose on the conclusions. Furthermore, physical and mental health measurements were not taken from those who participated in this research, which would be beneficial for future studies and allow quantitative methods to complement the qualitative methods already used. Such a mixed method approach would permit a more precise indication of how much participants' physical and mental health have improved as a result of their involvement in sport or other physical activity promotion programs. While obesity served as the impetus for the grant program in Texas, conclusive results cannot be presented for how participants' body weight or body composition were altered in the three communities. It is essential to note, though, that there are many other health measures that could be taken and an absence of obesity does not represent the presence of health (LeBesco, 2011). Finally, the benefits of conducting interviews were evident by the detailed descriptions of participants' physical activity. The self-report approach used in this study is particularly suitable when researchers are attempting to identify the contexts in which a given population is most likely to engage in prolonged physical activity behavior or evaluate historical physical activity behaviors (Troiano, Gabriel, Welk, Owen, \& Sternfeld, 2012). However, it should be noted that such methods may not be the most precise measurement of individual physical activity given the dependence on participants' recollections that such an approach requires. Self-reported methods 
may also not fully capture individuals' physical activity related to occupational, domestic, or transport domains.

\section{Conclusion}

Sport is not a trivial activity. However, it has often been treated as such in policymaking. As awareness increases about the significant role that sport can play in health promotion, practitioners will have another avenue to reach various groups of people that are not attracted to other forms of physical activity (e.g., Hartmann, 2003; Schulenkorf \& Thomson, 2011; Sherry, 2010; Sherry \& Strybosch, 2012). The value placed on sport as a tool for physical activity promotion should also increase as program leaders begin to see the holistic health benefits possible through sport and how those benefits need to be deliberately worked toward. The importance of deliberately structuring sport and other physical activity programs and ensuring that people experience benefits from their participation cannot be stressed enough. However, sport is also not a panacea. An exaggeration of what sport can do and a lack of effective evaluation limits the present and future use of sport as a policy tool, including for public health. As both Levermore (2008) and Coalter (2010) have discussed, in a variety of international contexts sport has been assumed to be an unquestionably sound aid for development initiatives when in fact many development claims have been left unsubstantiated. Sport will likely need to work in conjunction with other forms of physical activity and non-sport program elements in order to have a holistic effect that reaches beyond the program setting (Green, 2008). Even if that effect is small for each individual, incremental improvements, as Fineberg (2012) discussed, can result in substantial health and economic gains when experienced by thousands of people across a population. 
It is apparent from physical activity trends that sport managers and public health policymakers need to better manage and market sport based on the values and the benefits that individuals seek from their leisure-time physical activity. The results demonstrate that the hedonic rewards and social interaction (and the ensuing sense of community) are key to the participants' experience. With this understanding, programs can enhance awareness of leisuretime physical activity opportunities and serve to help align sport participation with prevalent social and cultural values in a community. Such an approach would help better address vital public health policy issues, give program leaders another means to encourage greater levels of physical activity, and demonstrate the distinctiveness and utility of sport. 


\section{References}

Armstrong, T., \& Bull, F. (2006). Development of the World Health Organization Global Physical Activity Questionnaire (GPAQ). Journal of Public Health, 14, 66-70.

Berg, B. K., \& Chalip, L. (2013). Regulating the emerging: A policy discourse analysis of mixed martial arts legislation. International Journal of Sport Policy and Politics, 5, 21-38.

Bergeron, M. F. (2007). Improving health through youth sports: Is participation enough? New Directions for Youth Development, 2007, 27-41.

Brownson, R. C., Boehmer, T. K., \& Luke, D. A. (2005). Declining rates of physical activity in the United States: What are the contributors? Annual Review of Public Health, 26, 421443.

Casey, M. M., Payne, W. R., \& Eime, R. M. (2009). Partnership and capacity-building strategies in community sports and recreation programs. Managing Leisure, 14, 167-176.

Centers for Disease Control and Prevention. (2012, August 7). Physical activity. Retrieved from http://www.cdc.gov/physicalactivity/.

Chalip, L. (1995). Policy analysis in sport management. Journal of Sport Management, 9, 1-13.

Chalip, L. (1996). Critical policy analysis: The illustrative case of New Zealand sport policy development. Journal of Sport Management, 10, 310-324.

Chalip, L. (2006). Toward a distinctive sport management discipline. Journal of Sport Management, 20, 1-21. 
Chalip, L. (2011). The future past of the Amateur Sports Act: Developing American sport. Journal of Coaching Education, 4, 4-29.

Chalip, L., \& Johnson, A. (1996). Sports policy in the United States. In L. Chalip, A. Johnson, \& L. Stachura, (Eds), National sport policies: an international handbook (pp. 404-430). Westport, CT: Greenwood Press.

Chalip, L., Schwab, K., \& Dustin, D. (2010). Bridging the sport and recreation divide. Schole, $25,1-10$.

Chambliss, D. F. (1989). The mundanity of excellence: An ethnographic report on stratification and Olympic swimmers. Sociological Theory, 7, 70-86.

Cleland, V., Timperio, A., Salmon, J., Hume, C., Telford, A., \& Crawford, D. (2011). A longitudinal study of the family physical activity environment and physical activity among youth. American Journal of Health Promotion, 25, 159-167.

Coalter, F. (2007). Sports clubs, social capital and social regeneration: 'Ill-defined interventions with hard to follow outcomes? Sport in Society, 10, 537-559.

Coalter, F. (2010). The politics of sport-for-development: Limited focus programmes and broad gauge problems? International Review for the Sociology of Sport, 45, 295-314.

Coakley, J. (2008). Sports in society: issues \& controversies. New York, NY: McGraw-Hill.

Comstock, R. D., Knox, C., Yard, E., \& Gilchrist, J. (2006). Sports-related injuries among high school athletes-United States, 2005-06 school year. Morbidity and Mortality Weekly Report, 55, 1037-1040. 
Dixon, M. A., Warner, S. M., \& Bruening, J. E. (2008). More than just letting them play: The enduring impact of parental socialization on female sport involvement. Sociology of Sport Journal, 25, 538-559.

Eisenhardt, K. (1989). Building theories from case study research. The Academy of Management Review, 14, 532-550.

Fineberg, H. V. (2012). A successful and sustainable health system - How to get there from here. New England Journal of Medicine, 366, 1020-1027.

Fraser-Thomas, J. L., Cote, J., \& Deakin, J. (2005). Youth sport programs: An avenue to foster positive youth development. Physical Education and Sport Pedagogy, 10, 10-40.

Fraser-Thomas, J., Cote, J., \& Deakin, J. (2008). Examining adolescent sport dropout and prolonged engagement from a developmental perspective. Journal of Applied Sport Psychology, 20, 318-333.

Frisby, W. (2005). The good, the bad, and the ugly: Critical sport management research. Journal of Sport Management, 19, 1-12.

Gould, D., \& Carson, S. (2004). Myths surrounding the role of youth sports in developing Olympic champions. Youth Studies Australia, 23, 19-26.

Goulding, C. (2002). Grounded theory: A practical guide for management, business, and market researchers. London, England: Sage.

Green, B. C. (2005). Building sport programs to optimize athlete recruitment, retention, \& transition: Toward a normative theory of sport development. Journal of Sport Management, 19, 233-253. 
Green, B. C. (2008). Sport as an agent for social and personal change. In V. Girginov (Ed.), Management of sport development (pp. 129-146). Oxford, United Kingdom: Elsevier.

Green, L. W., \& Kreuter, M. W. (2005). Health program planning: An educational and ecological approach. (4 ${ }^{\text {th }}$ ed.). New York, NY: McGraw-Hill.

Grieve, J. \& Sherry, E. (2012). Community benefits of major sport facilities: The Darebin International Sports Centre. Sport Management Review, 15, 218-229. doi: 10.1016/j.smr.2011.03.001

Hartmann, D. (2003). Theorizing sport as social intervention: A view from the grassroots. Quest, $55,118-140$.

Katzmarzyk, P. T. (2010). Physical activity, sedentary behavior, and health: Paradigm paralysis or paradigm shift? Diabetes, 59, 2717-2725.

Katzmarzyk, P. T., \& Lee, I. M. (2012). Sedentary behavior and life expectancy in the USA: A cause-deleted life table analysis. British Medical Journal, 2. doi: 10.1136/bmjopen-2012000828.

Kellett, P., \& Warner, S. (2011). Creating communities that lead to retention: The social worlds and communities of umpires. European Sport Management Quarterly, 11, 475-498.

Kilpatrick, M., Hebert, E., \& Bartholomew, J. (2005). College students' motivation for physical activity: Differentiating men's and women's motives for sport participation and exercise. Journal of American College Health, 54, 87-94.

Kingdon, J. W. (1995). Agendas, alternatives, and public policies. (2nd ed.). New York, NY: HarperCollins. 
LeBesco, K., (2011). Neoliberalism, public health, and the moral perils of fatness. Critical Public Health, 21, 153-164.

Leek, D., Carlson, J. A., Cain, K. L, Henrichon, S., Rosenberg, D., Patrick, K., \& Sallis, J. F. (2011). Physical activity during youth sports practices. Archives of Pediatrics \& Adolescent Medicine, 165, 294-299.

Levermore, R. (2008). Sport in international development: Time to treat it seriously? The Brown Journal of World Affairs, 14, 55-66.

Lim, S. Y., Warner, S., Dixon, M., Berg, B., Kim, C., \& Newhouse-Bailey, M. (2011). Sport participation across national contexts: A multilevel investigation of individual and systemic influences on adult sport participation. European Sport Management Quarterly, $11,197-224$.

Lyons, K., \& Dionigi, R. (2007). Transcending emotional community: A qualitative examination of older adults and masters' sports participation. Leisure Sciences, 29, 375-389.

McCormack, J. B., \& Chalip, L. (1988). Sport as socialization: A critique of methodological premise. Social Science Journal. 25, 83-92.

Moore, L. V., Harris, C. D., Carlson, S. A., Kruger, J., \& Fulton, J. E. (2012). Trends in no leisure-time physical activity_United States, 1988-2010. Research Quarterly for Exercise and Sport, 83, 587-591.

Mowen, A. J., \& Baker, B. L. (2009). Park, recreation, fitness, and sport sector recommendations for a more physically active America: A white paper for the United States national physical activity plan. Journal of Physical Activity and Health, 6, S236-S244. 
Munhall, P. L. (2007). Nursing research: A qualitative perspective. (4th ed.). Sudbury, MA: Jones and Barlett.

Pate, R. R., Pratt, M., Blair, S. N., Haskell, W. L., Macera, C. A., Bouchard, C.,...Wilmore, J. H. (1995). Physical activity and public health. A recommendation from the Centers for Disease Control and Prevention and the American College of Sports Medicine. Journal of the American Medical Association, 273, 402-407.

Pressman, J. L., \& Wildavsky, A. (1973). Implementation. Berkeley, CA; University of California Press.

Royse, D., Thyer, B. A., Padgett, D. K., \& Logan, T. (2006). Program evaluation: An introduction (4th ed.). Belmont, CA: Thomson.

Salmon, J., Owen, N., Crawford, D., Bauman, A., \& Sallis, J. F. (2003). Physical activity and sedentary behavior: A population-based study of barriers, enjoyment, and preference. Health Psychology, 22, 178-188.

Sam, M. P. (2003). What's the big idea? Reading the rhetoric of a national sport policy process. Sociology of Sport Journal, 20, 189-213.

Sanger, J. (1996). The complete observer? A field research guide to observation. London, England: The Falmer Press.

Schulenkorf, N., \& Thomson, A. K. (2011). United through sports: Managing sport-fordevelopment programs in disadvantaged communities. In A. Ratna \& B. Lashua (Eds.), Community and inclusion in leisure research and sport development (pp. 55-76). Eastbourne, United Kingdom: Leisure Studies Association. 
Sherry, E. (2010). (Re)engaging marginalised groups through sport development programs: The Homeless World Cup. International Review for the Sociology of Sport, 45, 59-72.

Sherry, B., Blanck, H. M., Galuska, D. A., Pan, L., Dietz, W. H., \& Balluz, L. (2010). Vital signs: State-specific obesity prevalence among adults — United States, 2009. Morbidity and Mortality Weekly Report, 59, 1-5.

Sherry, E., \& Strybosch, V. (2012). A kick in the right direction: Longitudinal study of the Australian Community Street Soccer Program. Soccer and Society, 13, 495-509. doi:10.1080/14660970.2012.677225

Sherwood, N. E., \& Jeffery, R. W. (2000). The behavioral determinants of exercise: Implications for physical activity interventions. Annual Review of Nutrition, 20, 21-44.

Skinner, J., Zakus, D.H., \& Cowell, J. (2008). Development through sport: Building social capital in disadvantaged communities. Sport Management Review, 11, 253-275.

Smith, A., \& Bird, S. (2004). From evidence to policy: Reflections on emerging themes in health-enhancing physical activity. Journal of Sports Sciences, 22, 791-799.

Sparvero, E., Chalip, L., \& Green, B. C. (2008). United States. In B. Houlihan and M. Green (Eds.), Comparative elite sport development: systems, structures, and public policy (pp. 242-271). Oxford, England: Butterworth-Heinemann.

Taylor, W. C., Floyd, M. F., Whitt-Glover, M. C., \& Brooks, J. (2007). Environmental justice: A framework for collaboration between the public health and parks and recreation fields to study disparities in physical activity. Journal of Physical Activity and Health, 4, S50-S63. 
Troiano, R. P., Gabriel, K. K. P., Welk, G. J., Owen, N., \& Sternfeld, B. (2012). Reported physical activity and sedentary behavior: Why do you ask?. Journal of Physical Activity and Health, 9, S68-S75.

U.S. Department of Health and Human Services, Public Health Service, Office of the Surgeon General. (2010). The Surgeon General's vision for a healthy and fit nation. Retrieved from http://www.surgeongeneral.gov/library/obesityvision/obesityvision2010.pdf

U.S. Department of Health and Human Services, Healthy People 2020. (2013a). Healthy People 2020. Retrieved from http://www.healthypeople.gov/2020/topicsobjectives2020/objectiveslist.aspx?topicId=33

U.S. Department of Health and Human Services, Office of Disease Prevention and Health Promotion. (2013b). 2008 Physical Activity Guidelines. Retrieved from http://www.health.gov/paguidelines/

Vaeyens, R., Güllich, A., Warr, C. R., \& Philippaerts, R. (2009). Talent identification and promotion programmes of Olympic athletes. Journal of Sports Sciences, 27, 1367-1380.

Waddington, I. (2000). Sport and health: A sociological perspective. In J. Coakley \& E. Dunning (Eds.), Handbook of sports studies (pp. 408-421). London, England: Sage.

Wankel, L. M. (1997). The social psychology of physical activity. In J. E. Curtis \& S. J. Russell (Eds.), Physical activity in human experience (pp. 93 - 126). Champaign, IL: Human Kinetics. 
Warner, S. (2012). Sport and community. In G. B. Cunningham and J. N. Singer (Eds.), Sociology of sport and physical activity. (2nd ed.) (pp. 237-254). College Station, TX: Center for Sport Management Research and Education.

Warner, S., Bowers, M., \& Dixon, M. A. (2012). Team dynamics: A social networking perspective. Journal of Sport Management, 26, 53 - 66.

Warner, S., \& Dixon, M. A. (2011). Understanding sense of community from the athlete's perspective. Journal of Sport Management, 25, 257-271.

Warner, S., \& Dixon, M. A. (2013a). Sport and community on campus: Constructing a sport experience that matters. Journal of College Student Development, 54, 283-298.

Warner, S., \& Dixon, M. A. (2013b). Competition, gender, and the sport experience: An exploration among collegiate athletes. Sport, Education and Society. Advance online publication. doi: 10.1080/13573322.2013.774273

Warner, S., Dixon, M. A., \& Chalip, L. C. (2012). The impact of formal versus informal sport: Mapping the differences in sense of community. Journal of Community Psychology, 40, 983-1003.

Warner, S., Dixon, M., \& Leierer, S. (in press). Using youth sport to enhance parents' sense of community. Journal of Applied Sport Management.

Warner, S., Kerwin, S., \& Walker, M. (2013). Examining sense of community in sport: Developing the multidimensional 'SCS' Scale. Journal of Sport Management, 27, 349362. 
Warner, S., Shapiro, S. L., Dixon, M. A., Ridinger, L. L., \& Harrison, S. B. (2011). The football factor: Shaping community on campus. Journal of Issues in Intercollegiate Athletics, 4 , 236-256.

Weiss, R. S. (1994). Learning from strangers: The art and method of qualitative interview studies. New York, NY: The Free Press.

White, L. G. (1994). Policy analysis as discourse. Journal of Policy Analysis and Management, $13,506-525$.

World Health Organization. (2002). World Health Report 2002: Reducing risks, promoting healthy lifestyles. Geneva, Switzerland: World Health Organization. 